CLINICAL STUDY

\title{
Psychiatric characterization of children with genetic causes of hyperandrogenism
}

\author{
Sven C Mueller ${ }^{1}$, Pamela $\mathrm{Ng}^{2,6}$, Ninet Sinaii ${ }^{3}$, Ellen W Leschek ${ }^{4}$, Liza Green-Golan ${ }^{3}$, Carol VanRyzin ${ }^{3}$, \\ Monique Ernst ${ }^{1}$ and Deborah P Merke ${ }^{3,5}$ \\ ${ }^{1}$ Section of Developmental and Affective Neuroscience and ${ }^{2}$ Unit on Affective Cognitive Neuroscience, National Institute of Mental Health, NIH, $15 \mathrm{~K}$ North \\ Drive, Bethesda, Maryland 20892-1932, USA, ${ }^{3}$ NIH Clinical Center, NIH, Bethesda, Maryland 20892-1932, USA, ${ }^{4}$ Diabetes, Endocrinology and \\ Metabolic Diseases Division, National Institute of Diabetes and Digestive and Kidney Diseases, NIH, Bethesda, Maryland 20892-1932, USA, ${ }^{5}$ Program in \\ Developmental Endocrinology and Genetics, National Institute of Child Health and Human Development, National Institutes of Health, Bethesda, Maryland \\ 20892-1932, USA and ${ }^{6}$ School of Psychiatry, University of New South Wales, Sydney, NSW 2052, Australia \\ (Correspondence should be addressed to S C Mueller; Email: msven@mail.nih.gov)
}

\begin{abstract}
Objective: Very little is known about the mental health status in children with genetic causes of hyperandrogenism. This study sought to characterize psychiatric morbidity in this group.

Design/methods: Children (8-18 years) with the diagnosis of classic congenital adrenal hyperplasia (CAH) or familial male precocious puberty (FMPP) underwent a semi-structured psychiatric interview, the Kiddie Schedule for Affective Disorders and Schizophrenia-Present and Lifetime Version. According to sex and the literature, incidence of identified psychopathology was compared between the two endocrinological groups. We evaluated 72 patients: 54 CAH (21 females) and 18 FMPP.

Results: Twenty-four (44.4\%) CAH patients and 10 (55.6\%) FMPP patients met the criteria for at least one lifetime psychiatric diagnosis. Attention-deficit hyperactivity disorder (ADHD) was present in $18.2 \%$ of $\mathrm{CAH}$ males, $44.4 \%$ of FMPP males, and one case $(4.8 \%)$ in $\mathrm{CAH}$ females. A high rate of anxiety disorders was also found in all the three groups (17-21\%). Relative to females with CAH, the FMPP patients exhibited higher rates of ADHD. Age at diagnosis and the treatment modalities were not associated with psychopathology. Rates of psychiatric disorder, specifically ADHD and anxiety disorders, were higher than in the general population.

Conclusion: Although anxiety disorders may occur at an increased rate in children with chronic illness, androgens may contribute to higher risk for psychopathology in pediatric patients with genetic cause of excess androgen. Early diagnosis and treatment of childhood hyperandrogenism is essential for optimal development. The results suggest that assessment for psychiatric disorders should be part of the routine evaluation of these patients.
\end{abstract}

European Journal of Endocrinology 163 801-810

\section{Introduction}

Complex developmental and structural changes in the human brain begin in the first trimester (1) and endure well into early adulthood (2). An impact of androgens on the development of sexual dimorphism of the brain during adolescence has been described recently $(3,4)$. Perturbations in exposure to sex steroids during this sensitive developmental period can manifest in behavioral changes $(5,6)$. The timing, duration, and level of hormonal exposure all are likely modulators of the effects of hormones on the developing brain.

The relevance of androgens in the development of psychopathology has been suggested by sex-related differences in the prevalence, course and treatment response of several psychiatric disorders. Some investigators have proposed a role of androgen in the male dominance of certain psychiatric disorders such as pervasive developmental disorders (7) or Tourette's syndrome (8). For example, attention-deficit hyperactivity disorder (ADHD) and conduct disorder, both around twice as likely in boys than girls $(9,10)$, have been found to be associated with the androgen receptor (AR) gene (11). A role of androgen in the development of psychopathology is further corroborated by preliminary findings of abnormal local gray matter volume or concentration in striatum and medial temporal lobe in studies with predominantly male patients with ADHD, conduct disorder, or pervasive developmental disorder (12-15). Taken together, evidence of hormonal influences on emotional reactivity, brain structure and function, and behavior would suggest that youths with hyperandrogenism might be at risk for developing psychiatric disorders.

Children who are exposed to excess androgen early in life due to genetic disorders of steroidogenesis offer a 
natural model in which to study the potential effects of androgen on the developing brain. The most common cause of hyperandrogenism in childhood is classic congenital adrenal hyperplasia $(\mathrm{CAH})$, an autosomal recessive disorder characterized by cortisol deficiency and excess androgen of adrenal origin (16). Studies in females suffering from CAH have documented a higher than expected prevalence of male-typical traits and behaviors $(17,18)$, more maletypical childhood play (19), show more interest in male-typical activities and careers (17), and exhibit more aggression (18) than unaffected females. Although findings in males with $\mathrm{CAH}$ have been mixed (19-21), favorable psychological health, based on the Child Behavior Checklist (CBCL) (22), has been reported in both male and female $\mathrm{CAH}$ patients treated early in life (23). Previous studies have specifically investigated sexual identity (24) or behavioral traits associated with autism in females with CAH (25) but, to our knowledge, no comprehensive psychiatric evaluations have been reported. Behavioral changes such as increased levels of aggression have also been observed in males with familial male precocious puberty (FMPP) (26), a genetic male-limited cause of precocious puberty due to activating mutations of the LH receptor $(27,28)$. No studies have reported on rates of psychopathology in this rare congenital syndrome (up to 9 in 1 million; Orphanet).

Although the CBCL is frequently used as a screening instrument, a structured diagnostic interview such as the Kiddie Schedule for Affective Disorders and Schizophrenia-Present and Lifetime Version (KSADSPL) may be necessary to identify the clinical criteria for the presence of psychopathology in children (29). The KSADS is a standardized, reliable, and semi-structured psychiatric diagnostic interview that generates Diagnostic and Statistical Manual of Mental Disorders (DSM-IV) psychiatric diagnoses with excellent test-retest reliability for present and lifetime diagnoses. Studies have also shown that the CBCL is less sensitive at detecting psychiatric disorders than a standardized psychiatric interview (30).

Thus, based on the surprising lack of formal psychiatric evaluations in disorders of androgen function, and on the widespread notion of a role of androgens in male dominance of psychiatric disorders, we sought to assess the presence of clinical psychopathology in children with two forms of known hyperandrogenism early in life, CAH and FMPP. To this aim, the KSADS-PL was used. We hypothesized that early and prolonged exposure to androgens might predispose children to risk for psychopathology. Moreover, given that $\mathrm{CAH}$ is characterized by excess androgen and also cortisol deficiency (16) and FMPP by selective testosterone excess (31), we evaluated differences in psychopathology between males and females with CAH and males with FMPP.

\section{Methods}

\section{Patients}

English-speaking patients aged 8-18 years with the diagnosis of CAH or FMPP were part of an ongoing natural history study of patients with excess androgen at the NIH Clinical Center (Clinical Trials \# NCT00250159). Upon a routine endocrine evaluation, all patients with a diagnosis of classic CAH or FMPP were invited to undergo psychiatric assessment. None refused to participate in this psychiatric evaluation. Patients were recruited from October 2002 through January 2009. Seventy-two adolescents were enrolled including 54 patients ( 21 females and 33 males) with CAH and 18 males with FMPP. The study was approved by the institutional review boards at the National Institute of Child Health and Human Development and the National Institute of Mental Health. Each patient or a parent gave written informed consent, and the children gave their assent.

\section{Study protocol}

All patients underwent a physical examination by a pediatric endocrinologist (E W L or D P M) as part of their routine evaluation. Height, weight, and body mass index (BMI) were recorded. Pubertal stage was assessed by physical examination according to the criteria of Marshall \& Tanner (32). In males, pubertal stage was assessed using a modified genital staging method based on the average volume of both the testes (33). Specifically, testicular volumes $<4 \mathrm{ml}$ were defined as stage $1 ; 4$ to $<8 \mathrm{ml}$ as stage $2 ; 8$ to $<12 \mathrm{ml}$ as stage 3 ; 12 to $<15 \mathrm{ml}$ as stage 4 and $\geq 15 \mathrm{ml}$ as stage 5 . Household socioeconomic status (SES) was determined according to the Hollingshead Scale, a four-factor index based on a composite of maternal and paternal education and occupational status (34). Within 1 to 2 days of their physical examination, patients underwent a psychiatric evaluation. However, because the objective for enrollment was endocrinological treatment and no mention was made a priori of psychiatric evaluation, any potential referral bias was unlikely to happen. Moreover, patients were recruited from all over the US and they were well distributed in terms of economic backgrounds.

All patients were assessed with the KSADS-PL. The parent $(85-90 \%$ of the time the mother was the parent respondent) and the child were interviewed separately about the child's behavior (29). Discrepancies in descriptions of behavior between parent and child were being recorded and also compared with teacher report cards or previous visits with pediatricians, and diagnosis was assigned by consensus among clinicians. Trained clinicians with graduate and postgraduate training and established inter-rater reliability (all $\kappa>0.80$ ) completed the KSADS-PL on every participant, and clinical assessments were made concurrent with 
the KSADS interview based on both parent and child report. Psychiatric disorders were grouped into four main categories: i) anxiety disorders (panic disorder, separation anxiety disorder, avoidant disorder/social phobia, overanxious/generalized anxiety, and obsessivecompulsive disorder); ii) disruptive behavioral disorders (ADHD, oppositional defiant disorder (ODD), and conduct disorder); iii) substance abuse (cigarette use, alcohol use, and drug abuse); iv) mood disorders (major depression, mania and hypomania); and v) other disorders (tic disorder, enuresis, encopresis, anorexia nervosa, and learning disorder).

\section{Statistical analysis}

Height SDS, weight SDS, and BMI SDS were determined using anthropometric reference data for US children (35). Owing to sex-specific prevalence rates for psychiatric disorders $(36,37)$, we compared three groups: $\mathrm{CAH}$ males, $\mathrm{CAH}$ females and FMPP. Demographic and clinical data comparisons of patient groups were performed using MANOVAs for continuous variables. For categorical variables, the Kruskal-Wallis test was used and, in case of significance, follow-up tests were conducted with the Mann-Whitney $U$ test. Similar tests of demographic and clinical variables were used to compare the $\mathrm{CAH}$ groups according to sex, and the presence or absence of various psychiatric diagnoses in the $\mathrm{CAH}$ and FMPP groups. A multivariable logistic regression was used to predict the presence of psychopathology in the two groups separately. To establish which factors contributed to risk for lifetime psychopathology, we included age at diagnosis, and history of GNRH analog (GNRHa) treatment for central puberty (yes/no). Severity of disease (salt-wasting (SW) versus simple-virilizing (SV)) was also included for the $\mathrm{CAH}$ patients and current medication for the FMPP patients. All tests were two-tailed with $\alpha$ set at 0.05 . A Stepdown Bonferroni (Holm) correction was applied to $P$ values derived from multiple comparisons for all post hoc tests. Adrenal hormone levels were log-transformed, as necessary.

For the comparison of each current group with the healthy and chronic disease population estimates, Fisher's exact test was used. Our estimates for mood disorders, anxiety disorders, ADHD as well as disruptive behavioral disorders were obtained from a large community study by Ford et al. (38) in youths. For the comparison of each current group with children and adolescents with other chronic diseases, estimates were obtained from a study by Davies et al. (39) that examined the prevalence rates in youths with epilepsy and diabetes. Given the potential methodological differences, such as differences in assessment, a conservative approach was adopted and all tests were corrected for multiple comparisons using the Stepdown Bonferroni (Holm) procedure. The data were analyzed using SPSS v 15 (Chicago, IL, USA) and SAS v 9.1 (Cary, $\mathrm{NC}$, USA). In addition, a review of the relevant studies of psychopathology in youths with or without chronic disorders is provided (Table 1) to facilitate comparison.

\section{Results}

\section{Sample characteristics}

The majority of patients participating in the study had $\mathrm{CAH}$ (Table 2). Two patients with $\mathrm{CAH}$ had classic 11-hydroxylase deficiency, and 52 patients had $\mathrm{CAH}$ due to classic 21-hydroxlase deficiency. Of the patients with classic $\mathrm{CAH}, 33$ were SW (13 females) and 19 were SV (8 females). All patients with $\mathrm{CAH}$ were on glucocorticoid replacement therapy (average hydrocortisone dose $12.6 \pm 4.5 \mathrm{mg} / \mathrm{m}^{2}$ per day). $\mathrm{CAH}$ patients with 21-hydroxylase deficiency were also treated with mineralocorticoid (fludrocortisone). Fifteen $(27.8 \%)$ patients with $\mathrm{CAH}$ and $13(72.2 \%)$ patients with FMPP were currently receiving or had received GNRHa for suppression of central puberty. Nine (50.0\%) patients with FMPP were receiving an anti-androgen (spironolactone) and aromatase inhibitor (arimidex) for treatment of their precocious pseudopuberty, while nine $(50.0 \%)$ patients with FMPP were not receiving medication.

Multivariate ANOVA indicated significant group differences on age of diagnosis $(P<0.001)$, bone age $(P=0.04)$, and SES $(P=0.026)$. All the three groups did not differ on the measurements of height $(P=0.06)$, weight $(P=0.20)$, BMI $(P=0.27)$, or IQ $(P=0.22)$. Post hoc comparisons revealed that $\mathrm{CAH}$ females and $\mathrm{CAH}$ males were diagnosed, on average, significantly earlier than FMPP $(P<0.001)$, and age at diagnosis did not differ between $\mathrm{CAH}$ males and $\mathrm{CAH}$ females $(P=0.33)$. Bone age of the FMPP group was more advanced than that of $\mathrm{CAH}$ females $(P=0.04)$ but not significantly different from $\mathrm{CAH}$ males $(P=0.16)$, while the $\mathrm{CAH}$ subgroups did not differ from one another $(P=1.00)$. SES differed only between FMPP and $\mathrm{CAH}$ males $(P=0.02)$ but not between FMPP and $\mathrm{CAH}$ females $(P=0.31)$. Again, no difference in SES between the $\mathrm{CAH}$ subgroups was present $(P=0.94)$. Relative to $\mathrm{CAH}$ males, FMPP boys showed more advanced sexual maturation, with larger testicular volume $(P<0.001)$ and more pubic hair $(P<0.001)$. FMPP boys had higher testosterone levels relative to both $\mathrm{CAH}$ boys $(P<0.001)$ and $\mathrm{CAH}$ girls $(P<0.001)$.

\section{Lifetime psychiatric diagnosis}

The psychiatric interview by means of the KSADS revealed that $24(44.4 \%)$ patients with $\mathrm{CAH}$ and $10(55.6 \%)$ patients with FMPP met the criteria for at least one psychiatric diagnosis in their lifetime (Table 3). The most common lifetime diagnoses were ADHD 


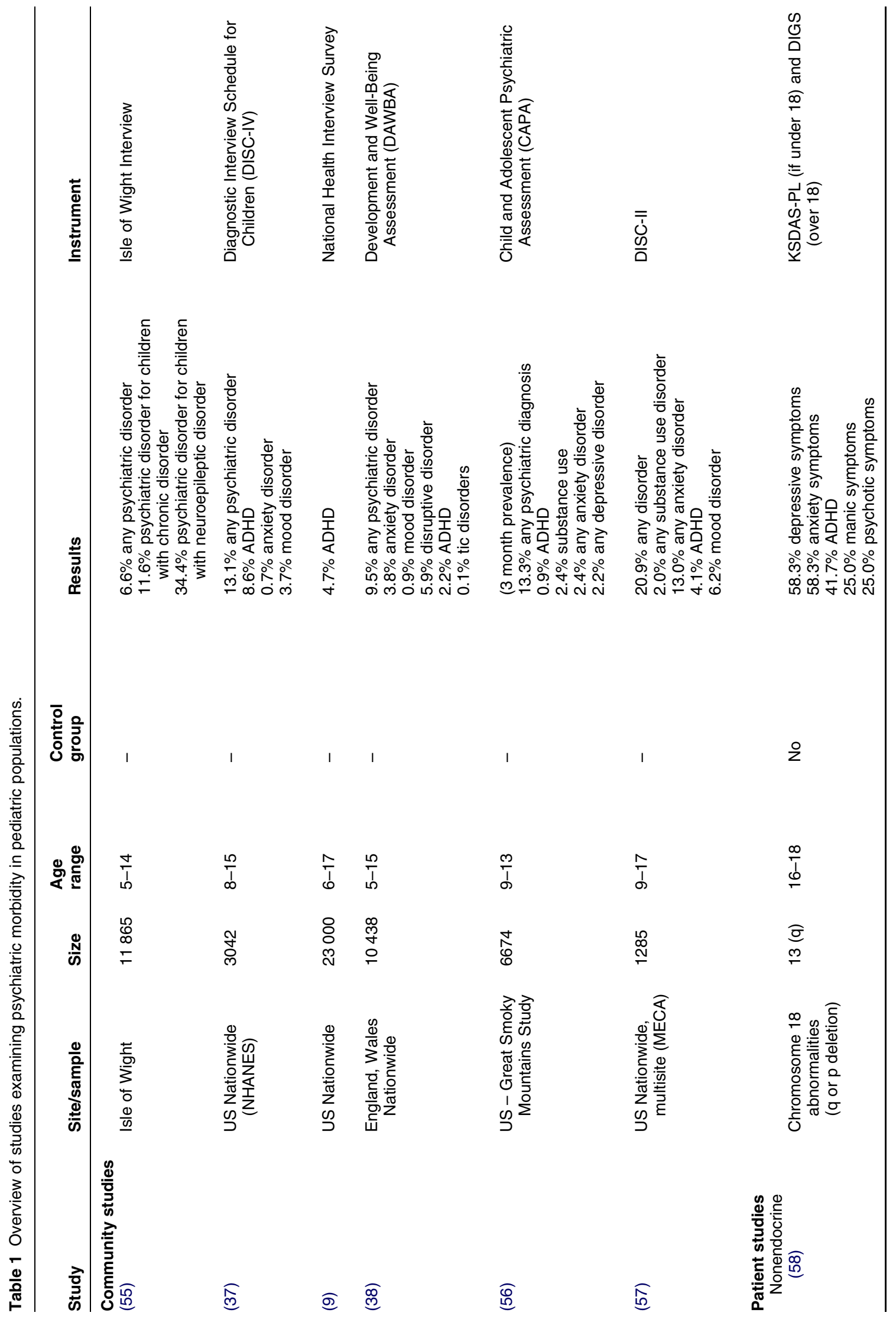

www.eje-online.org 


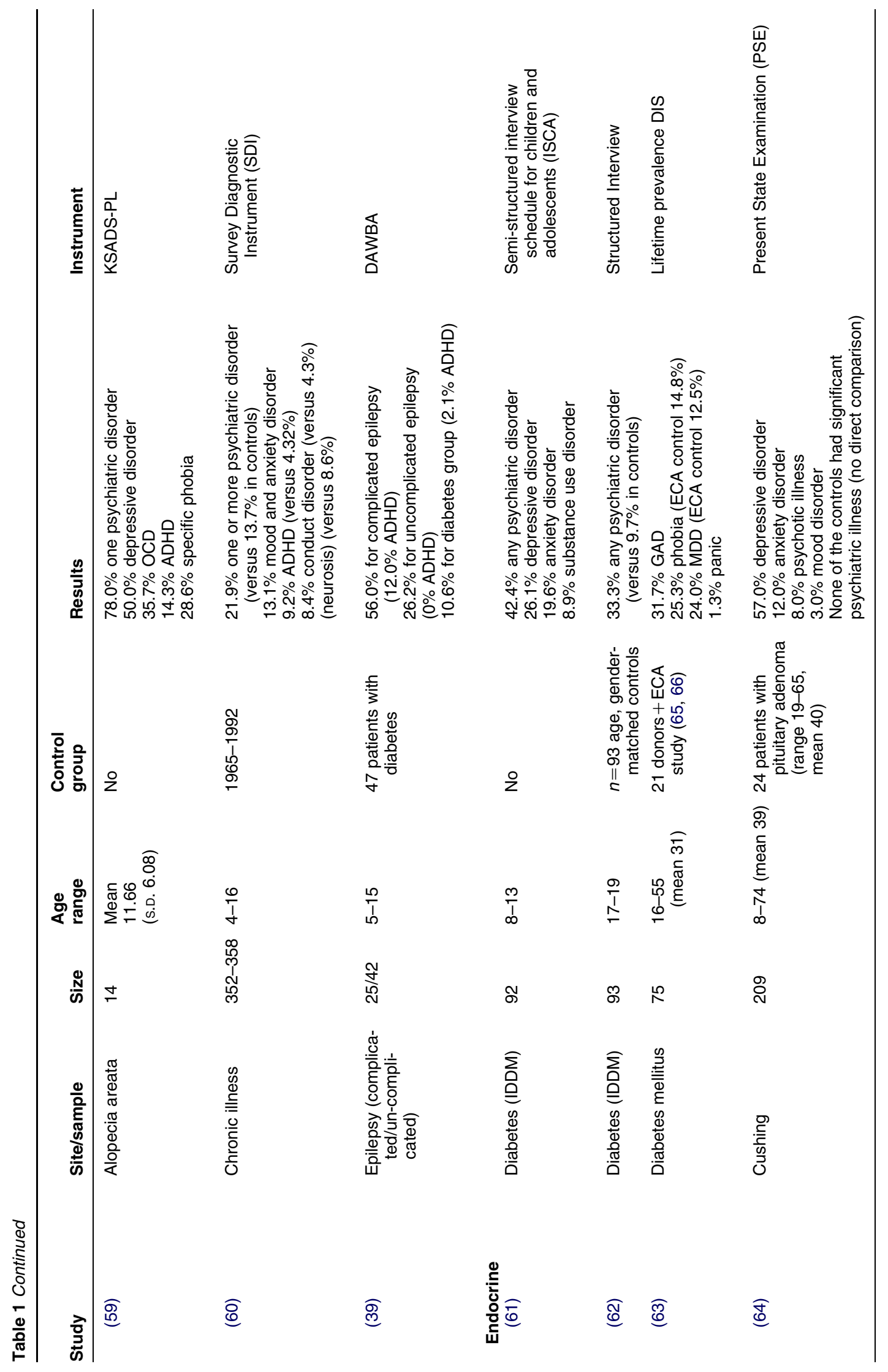


Table 2 Clinical characteristics of subjects with congenital adrenal hyperplasia (CAH) and familial male precocious puberty (FMPP). Data are mean \pm s.D., unless otherwise specified.

\begin{tabular}{|c|c|c|c|c|c|}
\hline & $\begin{array}{l}\text { CAH } \\
(n=54)\end{array}$ & $\begin{array}{l}\text { CAH females } \\
(n=21)\end{array}$ & $\begin{array}{l}\text { CAH males } \\
(n=33)\end{array}$ & $\begin{array}{l}\text { FMPP males } \\
(n=18)\end{array}$ & $\begin{array}{l}\text { Statistical } \\
\text { significance }\end{array}$ \\
\hline Age (years) & $12.5 \pm 2.6$ & $13.3 \pm 2.9$ & $12.0 \pm 2.4$ & $12.9 \pm 3.1$ & NS \\
\hline Age at diagnosis (years) & $1.0 \pm 1.6$ & $0.5 \pm 1.2$ & $1.3 \pm 1.7$ & $3.8 \pm 2.1$ & $P<0.001^{a, b}$ \\
\hline \multicolumn{6}{|l|}{ Ethnicity (\%) } \\
\hline White-not Latino & $50(92.6)$ & $20(95)$ & $31(94)$ & $16(88.9)$ & NS \\
\hline African-American & $2(3.7)$ & $1(5)$ & $1(3)$ & $1(5.6)$ & NS \\
\hline Hispanic & $2(3.7)$ & - & $1(3)$ & $1(5.6)$ & NS \\
\hline SES $^{\mathrm{C}}$ & $48 \pm 24$ & $52 \pm 25$ & $47 \pm 24$ & $67 \pm 30$ & $P<0.05^{a}$ \\
\hline $\mathrm{IQ}$ & $106+14$ & $104+12$ & $107+15$ & $99+16$ & NS \\
\hline Bone age (years) & $13.4 \pm 2.4$ & $13.1 \pm 3.1$ & $13.7 \pm 1.9$ & $15.1 \pm 2.9$ & $P<0.05^{\mathrm{b}}$ \\
\hline Height SDS & $-0.0 \pm 1.2$ & $-0 . \overline{4} \pm 1.2$ & $0.3 \pm 1.4$ & $0.4 \pm 1.4$ & NS \\
\hline Weight SDS & $0.9 \pm 1.4$ & $0.5 \pm 1.3$ & $1.1 \pm 1.4$ & $0.9 \pm 1.0$ & NS \\
\hline BMI SDS & $1.1 \pm 1.1$ & $0.8 \pm 1.1$ & $1.2 \pm 1.1$ & $0.9 \pm 0.9$ & NS \\
\hline \multicolumn{6}{|l|}{ Tanner stage } \\
\hline Pubic hair & $2.8 \pm 1.6$ & $3.2 \pm 1.5$ & $2.5 \pm 1.4$ & $3.9 \pm 1.1$ & $P<0.001^{\mathrm{a}}$ \\
\hline Testicular volume (males) & & - & $2.0 \pm 1.4$ & $4.0 \pm 1.0$ & $P<0.001^{\mathrm{a}}$ \\
\hline Breasts (females) & & $3.4 \pm 1.3$ & - & - & \\
\hline Testosterone (ng/dl) & & $60.1 \pm 78.8$ & $147.8 \pm 205.9$ & $382.4 \pm 179.6$ & $P<0.001^{a, b}$ \\
\hline
\end{tabular}

NS, not significant.

${ }^{\mathrm{a}} \mathrm{CAH}$ males versus FMPP

${ }^{\mathrm{b}} \mathrm{CAH}$ females versus FMPP.

${ }^{\mathrm{C}}$ The Hollingshead four-factor index of socioeconomic status (SES) based on a composite of maternal education, paternal education, maternal occupational status, and paternal occupational status (Hollingshead 1975). A higher score reflects lower SES.

(18.2\% in CAH males and $44.4 \%$ in FMPP), and separation anxiety disorder (18.2\% in $\mathrm{CAH}$ males). Comparisons between groups revealed significant differences in lifetime disruptive behavioral disorders $(P=0.036)$, specifically ADHD $(P<0.05)$. Post hoc follow-up comparisons between groups showed that FMPP boys exhibited higher ADHD rates than $\mathrm{CAH}$ girls $(P=0.016)$. All other comparisons did not remain significant.

When rates of psychiatric disorder in FMPP were compared with the estimated population prevalence rates, FMPP boys showed increased rates of anxiety disorders $(P=0.02)$, mood disorders $(P=0.03)$, disruptive behavioral disorders $(P<0.001)$, ADHD $(P<0.001)$, and tic disorders $(P=0.001)$. Boys with $\mathrm{CAH}$ showed increased rates relative to the population estimate in anxiety disorders $(P<0.001)$, disruptive behavioral disorders $(P<0.01)$, and ADHD $(P<0.01)$. By comparison, CAH females only showed increased rates of anxiety disorders relative to healthy adolescent females $(P<0.02)$.

When our data were compared with psychiatric morbidity in youths suffering from chronic disorder, our patient sample showed significantly elevated rates in ADHD relative to youths with uncomplicated epilepsy $(P=0.003)$ or diabetes $(P=0.009)$, but did not differ from youths with complicated epilepsy $(P=0.39)$.

\section{Co-morbidity of psychiatric disorder in the CAH subgroups}

Comparing all SW versus SV revealed a trend for lifetime mood disorders (both $P=0.06$ ). We also evaluated CAH type separated by sex. For males, a marginally significant difference between SW and SV emerged on mood disorders (both $P=0.05$ ). These data showed that $18 \%$ of SV males in comparison to no cases in SW males suffered from a mood disorder. By comparison, no differences between SW and SV CAH were present in females.

\section{Additional factors}

For the patients with $\mathrm{CAH}$, the presence or absence of lifetime psychiatric disorder did not differ according to current age, age at diagnosis, sex, SES, IQ, or history of treatment with GNRHa for central precocious puberty. In particular, age at diagnosis and history of treatment with GNRHa were not predictive of ADHD.

For the patients with FMPP, the presence or absence of lifetime psychiatric disorder did not differ according to current age, age at diagnosis, SES, IQ, current medication, or history of treatment with GNRHa for central precocious puberty. Particularly, these factors were also not predictive of ADHD, tic disorder or substance use disorder.

\section{Discussion}

The goal of this study was to characterize psychiatric co-morbidity in $\mathrm{CAH}$ and FMPP and bring to the attention of the primary provider the mental health needs of these youths.

Our patients with hyperandrogenism exhibited high rates of KSADS-derived psychopathology, with 33-55\% 
Table 3 Lifetime prevalence of psychiatric disorders ${ }^{\mathrm{a}}$ in patients with CAH or FMPP.

\begin{tabular}{|c|c|c|c|c|}
\hline & \multicolumn{2}{|r|}{ CAH } & \multirow{2}{*}{$\begin{array}{l}\text { FMPP } \\
(n=18)\end{array}$} & \multirow[b]{2}{*}{ Significance } \\
\hline & Female $(n=21)$ & Male $(n=33)$ & & \\
\hline Any disorder ${ }^{\mathrm{b}}$ & 7 (33.3) & $17(51.5)$ & $10(55.6)$ & NS \\
\hline Range of number of co-morbid disorders & $0-3$ & $0-6$ & $0-6$ & \\
\hline Anxiety disorders ${ }^{c}$ & $4(19.1)$ & $7(21.2)$ & $3(16.7)$ & NS \\
\hline Separation anxiety disorder & $2(9.5)$ & $6(18.2)$ & $1(5.6)$ & NS \\
\hline Avoidant disorder/social phobia & $1(4.8)$ & - & $2(11.2)$ & NS \\
\hline Agoraphobia/specific phobia & $1(4.8)$ & $2(6.0)$ & $1(5.6)$ & NS \\
\hline Generalized anxiety/overanxious & - & $1(3.0)$ & - & NS \\
\hline OCD & $1(4.8)$ & $1(3.0)$ & - & NS \\
\hline Mood disorders ${ }^{d}$ & - & $2(3.0)$ & $2(11.1)$ & NS \\
\hline Disruptive behavioral disorders ${ }^{\mathrm{e}}$ & $2(9.5)$ & $9(27.0)$ & $8(44.4)$ & $<0.05^{f}$ \\
\hline ADHD & $1(4.8)$ & $6(18.2)$ & $8(44.4)$ & $<0.05^{\dagger}$ \\
\hline Oppositional defiant disorder & $1(4.8)$ & $1(3.0)$ & $1(5.6)$ & NS \\
\hline Conduct disorder & - & $2(6.0)$ & $1(5.6)$ & NS \\
\hline Substance abuse & - & - & $2(11.1)$ & NS \\
\hline Other disorders ${ }^{\mathrm{h}}$ & $3(14.3)$ & $8(24.0)$ & $3(16.7)$ & NS \\
\hline Tic disorder & - & - & $2(11.1)$ & NS \\
\hline Learning disorder & - & $1(3.0)$ & - & NS \\
\hline Enuresis & $1(4.8)$ & $4(12.0)$ & - & NS \\
\hline Encopresis & $1(4.8)$ & - & - & NS \\
\hline Binge eating & - & - & - & NS \\
\hline
\end{tabular}

of the sample suffering from a psychiatric condition. In particular, while females with $\mathrm{CAH}$ showed a 33\% co-morbidity rate with a psychiatric disorder, both $\mathrm{CAH}$ males and FMPP showed a 51-56\% co-morbidity rate. Among the disorders, ADHD (18-44\%) and anxiety disorders $(16-21 \%)$ were the most prevalent. The relevance of androgens in the development of psychopathology has been suggested based on sex-related differences in the prevalence, course and treatment response of several psychiatric disorders. Conditions that show male preponderance include some anxiety disorders (e.g. childhood-onset obsessive-compulsive disorder), pervasive developmental disorders (e.g. autism), and disruptive behavioral disorders, such as ADHD, conduct disorder, tic disorder, and ODD (36, 40-43). Our data are in agreement with these observations.

The etiology of ADHD and the reason for the increased prevalence of ADHD in the male general population is unknown, but possible factors include genetic, and environmental factors (44). Although no comprehensive survey of ADHD prevalence using full DSM-IV (TR) criteria in the US has been conducted, the population prevalence has been estimated at $4.7 \%$ based on a sample of $\sim 23000$ cases (9). During the prenatal and early postnatal period, males have significantly higher levels of testosterone than females. Fetal testosterone measured in amniotic fluid has been found to be associated with sexually differentiated play behavior in school-aged males and females, implicating early testosterone exposure as having a key role in human behavior (45). Interestingly, a short secondto-fourth finger length ratio, a potential indirect measure of in utero androgen exposure, has been found to be associated with ADHD in boys, but not in girls (46). It has been suggested that there may be a threshold effect of androgen on the risk of ADHD, such that girls are not at risk. However, in this study of males and females, exposed to high levels of androgen in utero and during childhood, only males were found to have a higher prevalence of ADHD. This suggests that early exposure to androgens may be a risk factor for ADHD, but only in the presence of other male-specific risk factors. Although age at diagnosis was not a significant predictor of $\mathrm{ADHD}$, it is possible that the later diagnosis and delayed treatment in males contributed to the higher incidence of ADHD and that early treatment in females avoided such an effect. Larger and more strongly powered studies are needed to evaluate this potential contributing factor.

This study also found a high rate of anxiety disorders in all the three groups. The prevalence of anxiety disorders in childhood and adolescence in the normal population is estimated to be around 9.5\% (38). Although the etiology of anxiety disorders is not fully understood, evidence from both preclinical and clinical studies supports the contribution of corticotropin-releasing hormone $(\mathrm{CRH})$ 
in the expression of anxiety-related behaviors, mainly through CRH neurocircuits connecting the amygdala and locus coeruleus $(47,48)$. In CAH patients, increased CRH secretion is expected in the untreated or undertreated state. This increased CRH secretion reflects a block in cortisol production, leading to an overall elevation of CRH due to lack of feedback inhibition (49). In a previous study, we found decreased amygdala volume in $\mathrm{CAH}$ children, suggesting that alteration in the hypothalamicpituitary-adrenal axis affects the growth and development of the amygdala (49). CRH-induced alterations of the locus coeruleus and/or amygdala functioning may play a role in the development of anxiety disorders in CAH patients. However, the high incidence of anxiety in patients with FMPP suggests that sex steroids may also play a role in the pathophysiology of anxiety disorders. Preliminary research in the rodent on the impact of gonadal hormones on fear behavior supports such a conjecture (50). However, given that the directionality of this impact (anxiogenic versus anxiolytic) appears to be modulated by the duration of exposure and dosage, more clarifying research is needed (51).

Finally, 11\% of FMPP males showed the presence of a tic-related disorder. Prevalence rate in the general population has been estimated at $0.07 \%$ (38), with males being 3-4 times more likely to develop this disorder relative to females (43). Male dominance of tic disorders has been taken to suggest an influence of androgens (8). In support of this view, perturbations in the plasma levels of LH have been reported in Tourette's syndrome (52). Moreover, administration of antiandrogens in patients with Tourette's syndrome has been found to decrease symptoms (53), while use of anabolic steroids in male athletes with this disorder has been found to increase symptomatology (54). Although increased rate of Tourette's syndrome in FMPP is consistent with androgen involvement in tic disorders, future research would need to address this issue further.

One major limitation of examining psychiatric morbidity in youths with medical pathology is the difficulty of finding appropriate comparison groups. For example, collecting data on a sample of healthy volunteers would not adequately reflect prevalence rates in the general population. In fact, nation-wide studies with much larger samples have been conducted and are more likely to provide adequate estimates $(9,37)$. Second, a healthy control group does not control for experiencing a serious chronic medical condition. For example, while the rate of co-morbid psychiatric disorder in the general population (ages 5-14; sample 11865 youths) is estimated at $6.6 \%$, the prevalence rate for mental disorders for youths with chronic physical disorders has been estimated at 11.6 and $34.3 \%$ for children and adolescents with neuroepileptic disorders (55). The psychosocial stress of experiencing a chronic endocrine disorder early in life may have also been a contributing factor to the development of an anxiety disorder. Finally, we did not assess genetic risk for anxiety disorders or ADHD in families with $\mathrm{CAH}$ or FMPP, and a potential genetic contribution to psychiatric disorders in these families is unknown. Thus, direct comparisons and inferences are difficult and an ideal control group does not exist. Many prior studies do not have a control group $(58,59,61)$, cover a broad age range (64), or compare their findings to the literature (63) (Table 1). However, comparing the current rates with those found in prior studies in both chronic and healthy populations allowed us to provide a more general picture to facilitate comparison. Indeed, we found that our endocrine patients with genetic forms of hyperandrogenism had higher rates of ADHD than children with other chronic diseases (uncomplicated epilepsy and diabetes), and this higher rate was comparable with that reported with complicated epilepsy of childhood.

Previous studies have documented increased presence of traits associated with autism, but not autism per se, in females, but not males with $\mathrm{CAH}$ relative to controls (25). While the KSADS does not specifically cover autism spectrum disorders (ASD), it is unlikely that patients with a severe form of ASD may have passed through examination unnoticed given its clinical presentation. However, while it cannot be completely ruled out that patients may have suffered from mild ASD, the lack of autistic tendencies in males with CAH (25) suggests that it is unlikely that our current findings of increased psychopathology in CAH males were obscured by co-morbid autism. Likewise, while previous research has documented increased rates of gender identity issues in $\mathrm{CAH}$ (24), a disorder not covered by the KSADS, the goal of this study was to characterize more frequent childhood and adolescent psychiatric disorders.

In summary, the high rate of behavioral disturbances and the presence of symptoms of psychopathology in the $\mathrm{CAH}$ and FMPP groups underscore the mental health needs of these children. The current results suggest that assessment for psychiatric and behavioral disorders should be part of the routine evaluation of these patients. Preventive measures, such as counseling the families of children with CAH and FMPP to be more vigilant for detecting the early appearance of symptoms of psychopathology, are warranted. Our findings provide preliminary evidence that youth with hyperandrogenism may be at risk for anxiety disorders and males with genetic causes of hyperandrogenism may be at risk for ADHD and disruptive behavioral disorders. Further research is needed to define the role and underlying mechanisms of hormone imbalances in the development of pediatric psychopathology.

\section{Declaration of interest}

D P Merke is a Commissioned Officer in the US Public Health Service. S C Mueller, P Ng, N Sinaii, E W Leschek, L Green-Golan, C VanRyzin, and $M$ Ernst have nothing to declare. D P Merke received research funds from Phoqus Pharmaceuticals during 2007-2008. 


\section{Funding}

This research was supported (in part) by the Intramural Research Programs of the Eunice Kennedy Shriver National Institute of Child Health and Human Development (NICHD), the National Institute of Mental Health (NIMH), and the National Institutes of Health Clinical Center and (in part) by the Congenital Adrenal Hyperplasia Research, Education and Support (CARES) Foundation.

\section{Acknowledgements}

The authors are grateful to the patients for their participation in this study and Ms Elizabeth Schroth for her assistance with data collection. We would also like to thank three anonymous reviewers for their helpful comments in improving the earlier versions of this manuscript.

\section{References}

1 Levitt P. Structural and functional maturation of the developing primate brain. Journal of Pediatrics 2003143 S35-S45. (doi:10. 1067/S0022-3476(03)00400-1)

2 Gogtay N, Giedd JN, Lusk L, Hayashi KM, Greenstein D, Vaituzis AC, Nugent TF III, Herman DH, Clasen LS, Toga AW, Rapoport JL \& Thompson PM. Dynamic mapping of human cortical development during childhood through early adulthood. PNAS 2004101 8174-8179. (doi:10.1073/pnas.0402680101)

3 Paus T, Nawaz-Khan I, Leonard G, Perron M, Pike GB, Pitiot A, Richer L, Susman E, Veillette S \& Pausova Z. Sexual dimorphism in the adolescent brain: role of testosterone and androgen receptor in global and local volumes of grey and white matter. Hormones and Behavior 200957 63-75. (doi:10.1016/j.yhbeh.2009.08.004)

4 Neufang S, Specht K, Hausmann M, Gunturkun O, HerpertzDahlmann B, Fink GR \& Konrad K. Sex differences and the impact of steroid hormones on the developing human brain. Cerebral Cortex 200919 464-473. (doi:10.1093/cercor/bhn100)

5 Parylak SL, Caster JM, Walker QD \& Kuhn CM. Gonadal steroids mediate the opposite changes in cocaine-induced locomotion across adolescence in male and female rats. Pharmacology, Biochemistry, and Behavior 200889 314-323. (doi:10.1016/ j.pbb.2008.01.003

6 Schulz KM, Zehr JL, Salas-Ramirez KY \& Sisk CL. Testosterone programs adult social behavior before and during, but not after, adolescence. Endocrinology 2009150 3690-3698. (doi:10.1210/ en.2008-1708)

7 Baron-Cohen S, Knickmeyer RC \& Belmonte MK. Sex differences in the brain: implications for explaining autism. Science $2005 \mathbf{3 1 0}$ 819-823. (doi:10.1126/science.1115455)

8 Peterson BS, Leckman JF, Scahill L, Naftolin F, Keefe D, Charest NJ \& Cohen DJ. Steroid hormones and CNS sexual dimorphisms modulate symptom expression in Tourette's syndrome. Psychoneuroendocrinology 199217 553-563. (doi:10.1016/ 0306-4530(92)90015-Y)

9 Pastor PN \& Reuben CA. Diagnosed attention deficit hyperactivity disorder and learning disability: United States, 2004-2006. National Center for Health Statistics. Vital and Health Statistics $2008101-14$.

10 Nock MK, Kazdin AE, Hiripi E \& Kessler RC. Prevalence, subtypes, and correlates of DSM-IV conduct disorder in the National Comorbidity Survey Replication. Psychological Medicine 200636 699-710. (doi:10.1017/S0033291706007082)

11 Comings DE, Chen C, Wu S \& Muhleman D. Association of the androgen receptor gene (AR) with ADHD and conduct disorder. Neuroreport 1999 10 1589-1592. (doi:10.1097/00001756-199905140-00036)

12 Brieber S, Neufang S, Bruning N, Kamp-Becker I, Remschmidt H, Herpertz-Dahlmann B, Fink GR \& Konrad K. Structural brain abnormalities in adolescents with autism spectrum disorder and patients with attention deficit/hyperactivity disorder. Journal of Child Psychology and Psychiatry 200748 1251-1258. (doi:10. 1111/j.1469-7610.2007.01799.x)

13 Castellanos FX, Lee PP, Sharp W, Jeffries NO, Greenstein DK, Clasen LS, Blumenthal JD, James RS, Ebens CL, Walter JM, Zijdenbos A, Evans AC, Giedd JN \& Rapoport JL. Developmental trajectories of brain volume abnormalities in children and adolescents with attention-deficit/hyperactivity disorder. Journal of the American Medical Association $2002 \mathbf{2 8 8} 1740-1748$. (doi:10.1001/jama.288.14.1740)

14 Wang J, Jiang T, Cao Q \& Wang Y. Characterizing anatomic differences in boys with attention-deficit/hyperactivity disorder with the use of deformation-based morphometry. AJNR. American Journal of Neuroradiology 200728 543-547.

15 McAlonan GM, Suckling J, Wong N, Cheung V, Lienenkaemper N, Cheung C \& Chua SE. Distinct patterns of grey matter abnormality in high-functioning autism and Asperger's syndrome. Journal of Child Psychology and Psychiatry 200849 1287-1295. (doi:10. $1111 /$ j.1469-7610.2008.01933.x)

16 Merke DP \& Bornstein SR. Congenital adrenal hyperplasia. Lancet 2005365 2125-2136. (doi:10.1016/S0140-6736(05)66736-0)

17 Dittmann RW, Kappes MH, Kappes ME, Borger D, Stegner H, Willig RH \& Wallis H. Congenital adrenal hyperplasia. I: Genderrelated behavior and attitudes in female patients and sisters. Psychoneuroendocrinology $1990 \quad 15$ 401-420. (doi:10.1016/ 0306-4530(90)90065-H)

18 Pasterski V, Hindmarsh P, Geffner M, Brook C, Brain C \& Hines M. Increased aggression and activity level in 3- to 11-year-old girls with congenital adrenal hyperplasia $(\mathrm{CAH})$. Hormones and Behavior 200752 368-374. (doi:10.1016/j.yhbeh.2007.05.015)

19 Berenbaum SA \& Snyder E. Early hormonal influences on childhood sex-typed activity and playmate preferences: implications for the development of sexual orientation. Developmental Psychology 199531 31-42. (doi:10.1037/0012-1649.31.1.31)

20 Mathews GA, Fane BA, Conway GS, Brook CG \& Hines M. Personality and congenital adrenal hyperplasia: possible effects of prenatal androgen exposure. Hormones and Behavior 200955 285-291. (doi:10.1016/j.yhbeh.2008.11.007)

21 Berenbaum SA \& Resnick SM. Early androgen effects on aggression in children and adults with congenital adrenal hyperplasia. Psychoneuroendocrinology $1997 \quad 22$ 505-515. (doi:10.1016/S0306-4530(97)00049-8)

22 Achenbach TM \& Edelbrock C. Manual for the Child Behavior Checklist and Revised Child Behavior Profile Burlington, VT: Queen City Printers, 1983.

23 Berenbaum SA, Korman Bryk K, Duck SC \& Resnick SM. Psychological adjustment in children and adults with congenital adrenal hyperplasia. Journal of Pediatrics 2004144 741-746. (doi:10.1016/j.jpeds.2004.03.037)

24 Meyer-Bahlburg HFL, Dolezal C, Baker SW, Ehrhardt AA \& New MI. Gender development in women with congenital adrenal hyperplasia as a function of disorder severity. Archives of Sexual Behavior 200635 667-684. (doi:10.1007/s10508-006-9068-9)

25 Knickmeyer R, Baron-Cohen S, Fane BA, Wheelwright S, Mathews GA, Conway GS, Brook CGD \& Hines M. Androgens and autistic traits: a study of individuals with congenital adrenal hyperplasia. Hormones and Behavior 200650 148-153. (doi:10. 1016/j.yhbeh.2006.02.006)

26 Laue L, Kenigsberg D, Pescovitz OH, Hench KD, Barnes KM, Loriaux DL \& Cutler GB Jr. Treatment of familial male precocious puberty with spironolactone and testolactone. New England Journal of Medicine 1989 320 496-502. (doi:10.1056/NEJM198902233200805)

27 Shenker A, Laue L, Kosugi S, Merendino JJ Jr, Minegishi T \& Cutler GB Jr. A constitutively activating mutation of the luteinizing hormone receptor in familial male precocious puberty. Nature 1993365 652-654. (doi:10.1038/365652a0)

28 Latronico AC, Anasti J, Arnhold IJ, Mendonca BB, Domenice S, Albano MC, Zachman K, Wajchenberg BL \& Tsigos C. A novel mutation of the luteinizing hormone receptor gene causing male gonadotropin-independent precocious puberty. Journal of Clinical Endocrinology and Metabolism 199580 2490-2494. (doi:10. $1210 /$ jc.80.8.2490) 
29 Kaufman J, Birmaher B, Brent D, Rao U, Flynn C, Moreci P, Williamson D \& Ryan N. Schedule for Affective Disorders and Schizophrenia for School-Age Children-Present and Lifetime Version (K-SADS-PL): initial reliability and validity data. Journal of the American Academy of Child and Adolescent Psychiatry 199736 980-988. (doi:10.1097/00004583-199707000-00021)

30 Wassenberg R, Max JE, Koele SL \& Firme K. Classifying psychiatric disorders after traumatic brain injury and orthopaedic injury in children: adequacy of K-SADS versus CBCL. Brain Injury 200418 377-390. (doi:10.1080/02699050310001617325)

31 Leschek EW. Familial male-limited precocious puberty. Endocrinologist 200414 148-151. (doi:10.1097/01.ten.0000127927. $01216.90)$

32 Marshall WA \& Tanner JM. Variations in pattern of pubertal changes in girls. Archives of Disease in Childhood $1969 \mathbf{4 4}$ 291-303. (doi:10.1136/adc.44.235.291)

33 Zachmann M, Prader A, Kind HP, Hafliger H \& Budliger H. Testicular volume during adolescence. Cross-sectional and longitudinal studies. Helvetica Paediatrica Acta 197429 61-72.

34 Hollingshead A. Four Factor Index of Social Status. Unpublished manuscript, Department of Sociology, Yale University, New Haven, CT, 1975.

35 Centers for Disease Control and Prevention. In Epi Info version 3.32, Department of Health and Human Services, CDC, USA 2000.

36 Zahn-Waxler C, Shirtcliff EA \& Marceau K. Disorders of childhood and adolescence: gender and psychopathology. Annual Review of Clinical Psychology 20084 275-303. (doi:10.1146/annurev. clinpsy.3.022806.091358)

37 Merikangas KR, He J-P, Brody D, Fisher PW, Bourdon K \& Koretz DS. Prevalence and Treatment of Mental Disorders Among US Children in the 2001-2004 NHANES. Pediatrics $2010 \mathbf{1 2 5}$ 75-81. (doi:10.1542/peds.2008-2598)

38 Ford T, Goodman R \& Meltzer H. The British Child and Adolescent Mental Health Survey 1999: the prevalence of DSM-IV disorders. Journal of the American Academy of Child and Adolescent Psychiatry 2003 42 1203-1211. (doi:10.1097/00004583-200310000-00011)

39 Davies S, Heyman I \& Goodman R. A population survey of mental health problems in children with epilepsy. Developmental Medicine and Child Neurology 200345 292-295. (doi:10.1111/j.14698749.2003.tb00398.x)

40 Rubinow DR \& Schmidt PJ. Androgens, brain, and behavior American Journal of Psychiatry 1996153 974-984.

41 van Goozen SH, van den Ban E, Matthys W, Cohen-Kettenis PT, Thijssen JH \& van Engeland H. Increased adrenal androgen functioning in children with oppositional defiant disorder: a comparison with psychiatric and normal controls. Journal of the American Academy of Child and Adolescent Psychiatry 200039 1446-1451. (doi:10.1097/00004583-200011000-00020)

42 Nigg JT. What Causes ADHD? Understanding What Does Wrong and Why New York: The Guilford Press, 2006.

43 Bradshaw JL. Developmental Disorders of the Frontostriatal System: Neuropsychological, Neuropsychiatric and Evoluntionary Perspectives New York: Psychology Press, 2002.

44 Biederman J \& Faraone SV. Attention-deficit hyperactivity disorder. Lancet 2005366 237-248. (doi:10.1016/S0140-6736(05)66915-2)

45 Auyeung B, Baron-Cohen S, Ashwin E, Knickmeyer R, Taylor K, Hackett G \& Hines M. Fetal testosterone predicts sexually differentiated childhood behavior in girls and in boys. Psychological Science 200920 144-148. (doi:10.1111/j.1467-9280.2009. 02279.x)

46 Martel MM, Gobrogge KL, Breedlove SM \& Nigg JT. Masculinized finger-length ratios of boys, but not girls, are associated with attention-deficit/hyperactivity disorder. Behavioral Neuroscience 2008122 273-281. (doi:10.1037/0735-7044.122.2.273)

47 Arborelius L, Owens MJ, Plotsky PM \& Nemeroff CB. The role of corticotropin-releasing factor in depression and anxiety disorders. Journal of Endocrinology 1999160 1-12. (doi:10.1677/joe.0.1600001)

48 Shepard JD, Barron KW \& Myers DA. Corticosterone delivery to the amygdala increases corticotropin-releasing factor mRNA in the central amygdaloid nucleus and anxiety-like behavior. Brain Research 2000861 288-295. (doi:10.1016/S0006-8993(00)02019-9)
49 Merke DP, Fields JD, Keil MF, Vaituzis AC, Chrousos GP \& Giedd JN. Children with classic congenital adrenal hyperplasia have decreased amygdala volume: potential prenatal and postnatal hormonal effects. Journal of Clinical Endocrinology and Metabolism 200388 1760-1765. (doi:10.1210/jc.2002-021730)

50 Milad MR, Igoe SA, Lebron-Milad K \& Novales JE. Estrous cycle phase and gonadal hormones influence conditioned fear extinction. Neuroscience 2009164 887-895. (doi:10.1016/j.neuroscience.2009.09.011)

51 Clark AS \& Henderson LP. Behavioral and physiological responses to anabolic-androgenic steroids. Neuroscience and Biobehavioral Reviews 200327 413-436. (doi:10.1016/S0149-7634(03)00064-2)

52 Sandyk R, Bamford CR, Binkiewicz A \& Finley PR. Gonadotropin deficiency in Tourette's syndrome: a preliminary communication. International Journal of Neuroscience 198842 121-125. (doi:10. 3109/00207458808985766)

53 Peterson BS, Zhang H, Anderson GM \& Leckman JF. A double-blind, placebo-controlled, crossover trial of an antiandrogen in the treatment of Tourette's syndrome. Journal of Clinical Psychopharmacology 199818 324-331. (doi:10.1097/00004714-199808000-00013)

54 Leckman JF \& Scahill L. Possible exacerbation of tics by androgenic steroids. New England Journal of Medicine 19903221674.

55 Rutter TJ \& Whitmore K. Education, Health, and Behavior London: Longmans, Green \& Co., 1970.

56 Costello EJ, Mustillo S, Erkanli A, Keeler G \& Angold A. Prevalence and development of psychiatric disorders in childhood and adolescence. Archives of General Psychiatry 200360 837-844. (doi:10.1001/archpsyc.60.8.837)

57 Shaffer D, Fisher P, Dulcan MK, Davies M, Piacentini J, SchwabStone ME, Lahey BB, Bourdon K, Jensen PS, Bird HR, Canino G, Regier DA \& The NIMH. Diagnostic Interview Schedule for Children Version 2.3 (DISC- 2.3): description, acceptability, prevalence rates, and performance in the MECA study. Journal of the American Academy of Child and Adolescent Psychiatry 199635 865-877. (doi:10.1097/00004583-199607000-00012)

58 Zavala J, Ramirez M, Medina R, Heard P, Carter E, Crandall A, Hale D, Cody J \& Escamilla M. Psychiatric syndromes in individuals with chromosome 18 abnormalities. American Journal of Medical Genetics. Part B, Neuropsychiatric Genetics 2010 153B 837-845.

59 Ghanizadeh A. Comorbidity of psychiatric disorders in children and adolescents with alopecia areata in a child and adolescent psychiatry clinical sample. International Journal of Dermatology $2008 \mathbf{4 7}$ 1118-1120. (doi:10.1111/j.1365-4632.2008.03743.x)

60 Cadman D, Boyle M, Szatmari P \& Offord DR. Chronic illness, disability, and mental and social well-being: findings of the Ontario Child Health Study. Pediatrics 198779 805-813.

61 Kovacs M, Goldston D, Obrosky DS \& Bonar LK. Psychiatric disorders in youths with IDDM: rates and risk factors. Diabetes Care 199720 36-44. (doi:10.2337/diacare.20.1.36)

62 Blanz BJ, Rensch-Riemann BS, Fritz-Sigmund DI \& Schmidt MH. IDDM is a risk factor for adolescent psychiatric disorders. Diabetes Care 199316 1579-1587. (doi:10.2337/diacare.16.12.1579)

63 Popkin MK, Callies AL, Lentz RD, Colon EA \& Sutherland DE. Prevalence of major depression, simple phobia, and other psychiatric disorders in patients with long-standing type I diabetes mellitus. Archives of General Psychiatry 198845 64-68.

64 Kelly WF. Psychiatric aspects of Cushing's syndrome. Quarterly Journal of Medicine 199689 543-551.

65 Robins LN, Helzer JE, Weissman MM, Orvaschel H, Gruenberg E, Burke JD \& Regier DA. Lifetime prevalence of specific psychiatric disorders in three sites. Archives of General Psychiatry 198441 949-958.

66 Myers JK, Weissman MM, Tischler GL, Holzer CE, Leaf PJ, Orvaschel H, Anthony JC, Boyd JH, Burke JD, Kramer H \& Stoltzman R. Six month prevalence of psychiatric disorders in three communities. Archives of General Psychiatry 198441 959-967.

Received 25 August 2010

Accepted 31 August 2010 